Dhaka Univ. J. Biol. Sci. 23(2): 119-125, 2014 (July)

\title{
RELATIONSHIP BETWEEN HEAD LICE (PEDICULUS HUMANUS CAPITIS) INFESTATION AND NUTRITIONAL STATUS OF CHILDREN
}

\author{
Mt. Tahmina Karim, Sharmin Musa*, Dinesh Mondal ${ }^{1}$ and Hamida Khanum \\ Department of Zoology, University of Dhaka, Dhaka-1000, Bangladesh
}

Key words: Prevalence, Children, Pediculus humanus capitis, Nutritional status

\begin{abstract}
The prevalence of head lice (Pediculus humanus capitis) infestation and malnutrition affect among the children (1 to 7 years) in the area of Mirpur Bihari Camp, Dhaka was observed. A total of 300 children were examined during February 2011 to January 2012, and among them 59.67\% prevalence of head lice was observed. The height and weight for age was compared following $50^{\text {th }}$ percentile or standard deviation score (SD-score) of WHO/ NCHS reference standard. In case of WAZ (weight for age using Z-score value) of boys, moderate malnutrition was found in 2, 3, and 5 years age group and mild malnutrition was found in 1, 4, 6 and 7 years age group. In case of WHZ (weight for height of boys), mild malnutrition was found in age group 2, 3 and 5 years. In better growth children, $56.67 \%$ were infested by head lice, $56 \%$ in medium growth children and the highest $65.46 \%$ among the children with mild growth. The intensity of infestation was mostly mild and moderate.
\end{abstract}

\section{Introduction}

Head louse (Pediculus humanus capitis: Anoplura) is an obligate ectoparasite(1). Head lice infestation is a common, worldwide problem ${ }^{(2-3)}$. It causes irritation, annoyance and sleepiness apart from psychological and social distress. Being infested by head lice in an endemic area is very common but it seems that children are more susceptible due to their life style ${ }^{(4)}$. Head lice feeding on blood may lead to anemia ${ }^{(5)}$.

Head lice rely solely on human blood for growth and survival(8). Blood is sucked from scalp capillaries of the host. The impact of head lice on human health has been rarely investigated ${ }^{(9)}$ and a more detailed study is warranted owing to the high prevalence of pediculosis in children $(2,10)$. The objective of this study was to observe the prevalence of head lice infestation (Pediculosis) among the children and the relationship between head lice infestation and nutritional status of children up to seven years.

\section{Materials and Methods}

A cross sectional study was carried out during February, 2011 to January, 2012 among the children in Mirpur Bihari Camp, Dhaka. A total of three hundred children, 1 to 7 years old were examined for infestation of head lice.

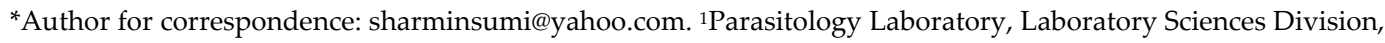
ICDDR, B, Mohakhali, Dhaka, Bangladesh. 
Anthropometric measurements are used in the assessment of nutritional status. A percentile refers to the position of the measurement value in relation to all (or 100\%) of the measurements for the reference population. $50^{\text {th }}$ percentile corresponds to the median.

Percentile $=\frac{\text { Observed value }}{\text { Median value of reference population }} \times 100$

The use of standard deviation (SD) scores is recommended by Waterlow et al.(11) for evaluating anthropometric data from less industrialist countries. But the median value of percentile and SD scores value are same and sometimes it is close to equal. The score is calculated using the following formula:

Z-score $\left(\right.$ or SD-score) $=\frac{\text { Observed value }- \text { Median reference value }}{\text { Standard deviation of reference population }}$

In case of WHZ

(Weight for height Z- score) $=\frac{\text { Weight of subject-median reference value of weight for height }}{\text { Median reference value }-1 \mathrm{SD} \text { below median reference value }}$

If the result of $\mathrm{SD}$ or $\mathrm{Z}$ score comes positive then it becomes normal and if it is -1 then it will be mild malnutrition and for -2 it becomes moderate malnutrition and it will be severe malnutrition for -3 .

Gomez classification ${ }^{(12)}$ is based on weight for age and uses the harvard reference data (Table 1). It has been used in this study to assess the nutritional status of the children infested with head lice.

Table 1. The Gomez classification.

\begin{tabular}{cll}
\hline $\begin{array}{c}\text { Expected weight } \\
\text { for age }(\%)\end{array}$ & Classification & $\begin{array}{l}\text { Category of } \\
\text { nutritional status }\end{array}$ \\
\hline$>90$ & Normal & Normal \\
$76-90$ & Mild malnutrition & $1^{\text {st }}$ degree malnutrition \\
$61-75$ & Moderate malnutrition & $2^{\text {nd }}$ degree malnutrition \\
$\leq 60$ & Severe malnutrition & $3^{\text {rd }}$ degree malnutrition \\
\hline
\end{tabular}

Nutritional status was assessed among the children by taking their height and measuring their body weight. Then height and weight for age (HAZ and WAZ using Z Scores value) and weight for height (WHZ using $Z$ Scores value or in other process $50^{\text {th }}$ percentile values of WHO standard) was compared with the observed height and weight of head lice infested children. The questionnaire was filled up for each child and their families through face to face interviewing. Prevalence rate was showed by calculating 
percentage of infestation and result was analyzed by statistical test. Statistical analysis was carried out by using Statistical Package for Social Science (SPSS) using chi-square test. For all statistical analyses, a significance level of $\mathrm{p}<0.05$ was adopted.

\section{Results and Discussion}

Among total of 300 children, the prevalence was $59.67 \%$ of head lice. In other parts of the world, the prevalence was found to be 33\% reported in Australia ${ }^{(10)}, 59.7 \%$ in Shillong, India(13), 35\% in Brazil(14) and $56.8 \%$ in Argentina ${ }^{(15)}$, which is attributed to the lower living standards and lack of awareness.

The median weight of boys and girls, expected median weight $\left(50^{\text {th }}\right.$ percentile value of WHO standard/Z-score value, SD-0) and status of malnutrition or standard deviation (SD) score among the children on the basis of age groups are shown in Table 2. In case of weight for age using Z-score value (WAZ) of boys, moderate malnutrition (in SD score result) was found in age group 2,3, and 5 years children. Mild malnutrition was found in $1,4,6$ and 7 years of age group. The weight of girls and degree of malnutrition or using $Z$ score result on the basis of age groups (WAZ) moderate malnutrition was found in age group 1, 2 and 3 years of children and mild malnutrition was found in 4, 5, 6 and 7 years age group (Table 2).

Table 2. Distribution of the study population on the basis of their weight $(\mathrm{kg})$ in relation to age (WAZ).

\begin{tabular}{|c|c|c|c|c|c|c|}
\hline \multicolumn{2}{|c|}{$\begin{array}{c}\text { Age group } \\
\text { (years) }\end{array}$} & \multirow{2}{*}{$\begin{array}{c}50^{\text {th }} \text { percentile } \\
(\mathrm{WHO} / \mathrm{NCHS} \\
\text { standard)/ Z-score } \\
\text { value (SD-0) } \\
\text { Median value }\end{array}$} & \multirow{2}{*}{$\begin{array}{c}\text { Children's } \\
\text { measured weight/ } \\
\text { observed value } \\
\text { Median value }\end{array}$} & \multirow[t]{2}{*}{$\begin{array}{c}\text { SD } \\
\text { score }\end{array}$} & \multirow[t]{2}{*}{$\begin{array}{c}\text { Percentiles } \\
(\%)\end{array}$} & \multirow[t]{2}{*}{$\begin{array}{c}\text { Nutritional status } \\
\text { (malnutrition) }\end{array}$} \\
\hline & & & & & & \\
\hline \multirow[t]{2}{*}{1} & Boys & 11.30 & 9 & -1.92 & 79.65 & Mild \\
\hline & Girls & 10.60 & 8 & -2.96 & 75.47 & Moderate \\
\hline \multirow[t]{2}{*}{2} & Boys & 13.35 & 10 & -2.58 & 74.90 & $"$ \\
\hline & Girls & 12.85 & 9 & -2.36 & 70.04 & $"$ \\
\hline \multirow[t]{2}{*}{3} & Boys & 15.55 & 11 & -2.6 & 70.74 & $"$ \\
\hline & Girls & 14.40 & 10 & -2.93 & 69.44 & $"$ \\
\hline \multirow[t]{2}{*}{4} & Boys & 17.60 & 14.25 & -1.68 & 80.96 & Mild \\
\hline & Girls & 16.20 & 13 & -1.88 & 80.25 & $"$ \\
\hline \multirow[t]{2}{*}{5} & Boys & 18.55 & 15 & -1.65 & 80.86 & $"$ \\
\hline & Girls & 18.55 & 15 & -1.65 & 80.86 & $"$ \\
\hline \multirow[t]{2}{*}{6} & Boys & 21.70 & 17.25 & -1.82 & 79.49 & $"$ \\
\hline & Girls & 20.55 & 17 & -1.45 & 82.73 & $"$ \\
\hline \multirow[t]{2}{*}{7} & Boys & 24.00 & 19 & -1.72 & 79.17 & $"$ \\
\hline & Girls & 23.20 & 19.75 & -1.13 & 85.13 & $"$ \\
\hline
\end{tabular}


In case of HAZ (height for age using $\mathrm{Z}$ score) of boys, moderate malnutrition was found among the children of age group 1, 3, 5 and 6 years and mild malnutrition was found in 2, 4 and 7 years of age group. It is also evident that the height of girls and degree of malnutrition or standard deviation (SD) score result among the children on the basis of age groups (HAZ) where moderate malnutrition was found in age group 1, 3, 4 and 6 years children and mild malnutrition was found in 2, 5 and 7 years of age group (Table 3).

Table 3. Distribution of the study population on the basis of their height $(\mathrm{cm})$ in relation to age (HAZ).

\begin{tabular}{|c|c|c|c|c|c|c|}
\hline \multicolumn{2}{|c|}{$\begin{array}{l}\text { Age } \\
\text { group } \\
\text { (years) }\end{array}$} & $\begin{array}{c}50^{\text {th }} \text { percentile }(\mathrm{WHO} \\
\text { standard)/Z-score } \\
\text { value }(\mathrm{SD}-0) \\
\text { Median value }\end{array}$ & $\begin{array}{c}\text { Children's } \\
\text { measured height/ } \\
\text { observed value } \\
\text { Median value }\end{array}$ & $\begin{array}{c}\text { SD } \\
\text { score }\end{array}$ & $\begin{array}{c}\text { Percentiles } \\
(\%)\end{array}$ & $\begin{array}{l}\text { Nutritional } \\
\text { status } \\
\text { (malnutrition) }\end{array}$ \\
\hline \multirow{3}{*}{1} & & & & & & \\
\hline & Boys & 81.45 & 73.66 & -2.60 & 90.44 & Moderate \\
\hline & Girls & 79.95 & 71.12 & -2.94 & 88.95 & $"$ \\
\hline \multirow[t]{2}{*}{2} & Boys & 87.20 & 82.55 & -1.50 & 94.67 & Mild \\
\hline & Girls & 86.20 & 81.28 & -1.49 & 94.29 & $"$ \\
\hline \multirow[t]{2}{*}{3} & Boys & 96.30 & 86.36 & -2.55 & 89.68 & Moderate \\
\hline & Girls & 97.45 & 86.36 & -2.88 & 88.62 & $"$ \\
\hline \multirow[t]{2}{*}{4} & Boys & 106.15 & 98.43 & -1.76 & 92.72 & Mild \\
\hline & Girls & 104.70 & 94.36 & -2.49 & 90.12 & Moderate \\
\hline \multirow[t]{2}{*}{5} & Boys & 112.75 & 101.60 & -2.37 & 90.11 & $"$ \\
\hline & Girls & 111.25 & 102.23 & -1.96 & 91.90 & Mild \\
\hline \multirow[t]{2}{*}{6} & Boys & 118.65 & 107.95 & -2.16 & 90.98 & Moderate \\
\hline & Girls & 117.35 & 106.68 & -2.07 & 90.90 & $"$ \\
\hline \multirow[t]{2}{*}{7} & Boys & 124.10 & 114.90 & -1.88 & 92.59 & Mild \\
\hline & Girls & 123.25 & 116.84 & -1.11 & 94.80 & $"$ \\
\hline
\end{tabular}

Table 4 showed that the weight of boys and degree of malnutrition or standard deviation (SD) score result on the basis of height of children (WHZ), mild malnutrition was found in age group 2, 3 and 5 years children and normal result was found in 1, 4, 6 and 7 years age group. In case of girls, the moderate malnutrition was found in age group 2 and 3 years children and normal result was found in 1, 4, 5, 6 and 7 years age group (Table 4).

It was observed that, among 95 children who have taken meals three times a day, $55.8 \%$ of them were infested by head lice whereas among 105 children who have taken food two times, infestation rate was $55.2 \%$ and children who have taken food one time per day, $68.0 \%$ of them were infested. The result was not statistically significant $(p>0.05)$ (Table 5). 
It was observed that, out of 90 children with heavy growth had $56.67 \%$ infestation by head lice, the children with of medium growth, $56 \%$ were infested, and those with mild growth had $65.46 \%$ infestation. Statistically the result was also not significant ( $\mathrm{p}>$ 0.05 ) (Table 6). There are reports on infestation and epidemiology of pediculosis ${ }^{(16)}$, but nutritional status of children due to the effect of pediculosis had not been done in Bangladesh. In Bangladesh, lice infestation is also a major public annoying problem.

Table 4. Distribution of the study population on the basis of their weight $(\mathrm{kg})$ in relation to height (WHZ).

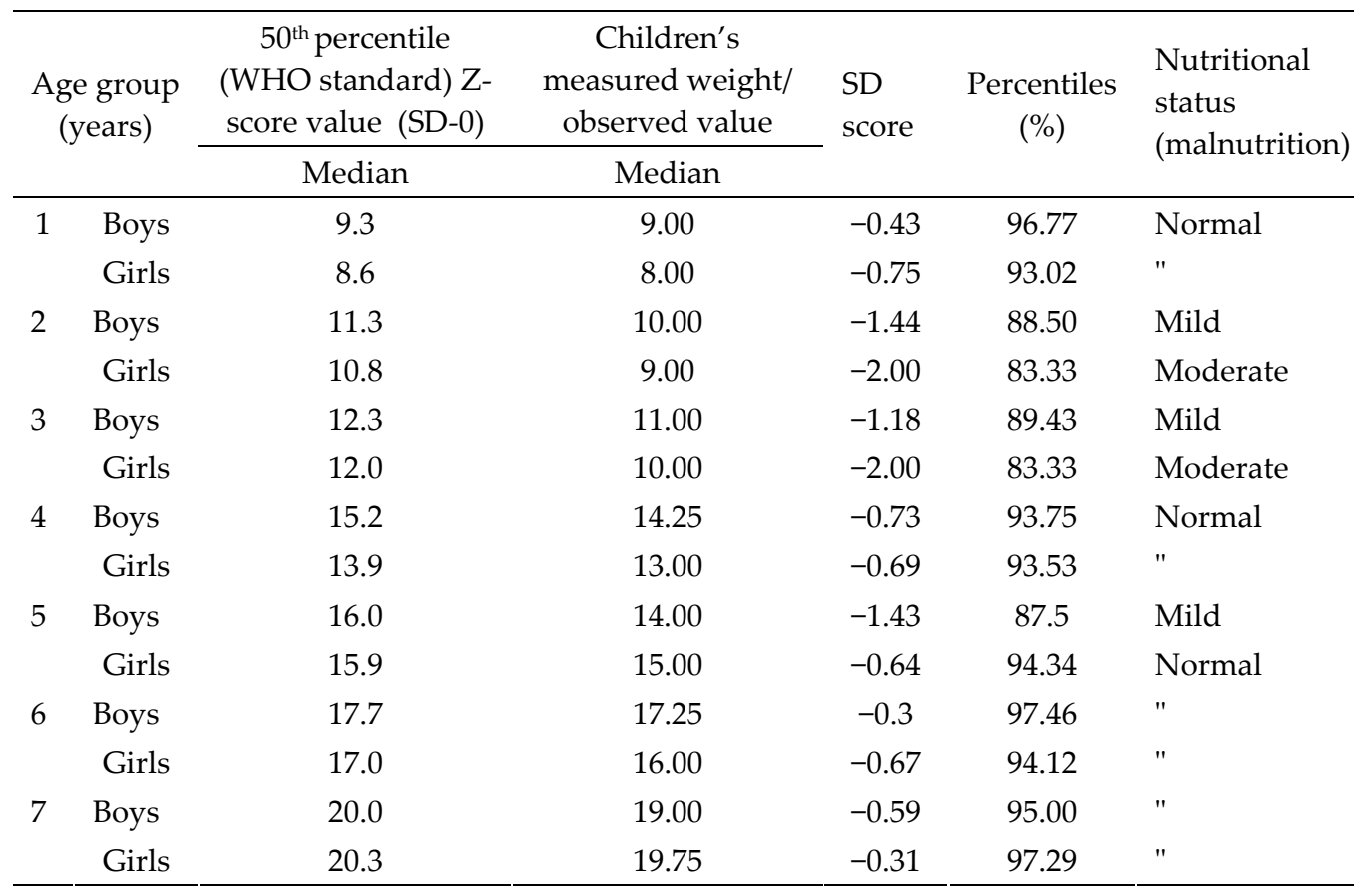

Table 5. Distribution of the population on the basis of number of meals per day.

\begin{tabular}{lccccc}
\hline Food taker/day & $\begin{array}{c}\text { No. of child } \\
\text { examined }\end{array}$ & $\begin{array}{c}\text { No. of infested } \\
\text { child }\end{array}$ & $\begin{array}{c}\text { Infested child } \\
(\%)\end{array}$ & $X^{2}$ & p value \\
\hline Three times & 95 & 53 & 55.8 & & \\
Two times & 105 & 58 & 55.2 & 4.335 & 0.114 \\
One time & 100 & 68 & 68.0 & & \\
\hline Total & 300 & 179 & & \\
\hline
\end{tabular}

The lice survive from a small amount of blood meal of its host; hence, iron deficiency anemia is a theoretic possibility. There was a small case series of patients with heavy lice infestation and profound iron deficiency anemia ${ }^{(17)}$. In the present study, in case of both the boys and girls, considering nutritional status, most of them were mild and 
moderately mal-nourished. The effect of head lice infestation on children was little because head lice may take small amount of blood that is negligible or number of lice is less in those children, so there was no effect on growth of child and time of taking food per day.

Table 6. Distribution of the study population by their growth.

\begin{tabular}{lccccc}
\hline $\begin{array}{l}\text { Growth of } \\
\text { child }\end{array}$ & $\begin{array}{c}\text { No. of child } \\
\text { examined }\end{array}$ & $\begin{array}{c}\text { No. of } \\
\text { infested child }\end{array}$ & $\begin{array}{c}\text { Infested child } \\
(\%)\end{array}$ & $\chi^{2}$ & p value \\
\hline Heavy growth & 90 & 51 & 56.67 & & \\
Medium growth & 100 & 56 & 56.00 & 2.426 & 0.297 \\
Mild growth & 110 & 72 & 65.46 & & \\
\hline Total & 300 & 179 & & & \\
\hline
\end{tabular}

The present investigation provides some factors which are related to pediculosis in human and its epidemiology in a group of people in Bangladesh. It revealed that there is little effect on nutrition and this is the first evidence of a provocative association of lice infestation and nutritional status of children due to ignorance and unhygienic habits of children and mother. There might be some antigenic effects of Pediculus on general health of children, which might cause loss of appetite and disturbed mental condition. Pediculosis can be prevented by better attention, personal hygiene with better association and good environmental condition.

\section{References}

1. Linardi PM, JR Botelho and M Maria 1988. Crendices e falsos conceitos que dificultam ações profiláticas contra o piolho e a pediculose "capitis". J Pediatria. 64: 248-255.

2. Gratz NG 1985-1997. Human Lice, their Prevalence, Control and Resistance to Insecticides, a Review, 1985-1997. Division of Control of Tropical Diseases, WHO Pesticide Evaluation Scheme: World Health Organization, 1997. Geneva, Switzerland Report WHO/CTD/ WHOPES/97.8.

3. Ha YC, JM Heo and HJ Kim 2000. Infestation status of head louse and treatment with lindane shampoo in children of primary school and kindergarten in Chinju-shi, Kyongsangnamdo, Korea. Korean J. Parasitol. 38: 41-43.

4. Mumcuoglu KY, J Miller, C Zamir and V Helbin 2002. The in vivo pediculicidal efficacy of a natural remedy. Israel Medical Assoc. J. 4(10): 790-93.

5. Slonka GF, TW Mc Kinley, JE Mc Croan, SP Sinclair, MG Schultz, F Hicks and N Hill 1976. Epidemiology of an outbreak of head lice in Georgia. Am. J. Trop. Med .Hyg. 25(5): 739743.

6. Buxton PA 1938. Studies on populations of head lice (Pediculus humanus capitis: Anoplura). II. Parasitology 30: 85-110.

7. Dodd C 2001. Treatment of head lice. BMJ 323: 1084.

8. Burgess IF 1995. Human lice and their management. Advances in Parasitology 36: 272-321. 
9. Speare R, DV Canyon and C Cahill 2000. Developing an evidence base for head lice and their control. Tropical Millennium Bugs. In: Proceedings of the Annual Scientific Meeting of the Australian College of Tropical Medicine at Noosa Heads. 54. Townsville, Australia.

10. Speare R and PG Buettner 1999. Head lice in pupils of a primary school in Australia and implications for control. Int. J. Dermatol. 38: 285-290.

11. Waterlow JC, R Buzina, W Keller, JM Lane, MZ Nichaman and JM Tanner 1977. The presentation and use of height and weight data for comparing the nutritional status of groups of children under the age of 10 years. Bulletin of the World Health Organization. 55: 489-498.

12. Gomez F, RR Galvan, S Frenk, J Cravioto Monoz, R Chavez and L Vazquez 1956. Mortality in second and third degree malnutrition. J. Trop. Ped. 2: 77-83.

13. Roy B and V Tandon 1992. Louse infestation in human population in Shillong, India. Hlth. Hyg. 13: 15-20.

14. Borges R and J Mendes 2002. Epidemiological aspects of head lice in children attending day care centres, urban and rural schools in Uberlândia, central Brazil. Mem. Inst. Oswaldo. Cruz. 97(2): 189-192.

15. Milano AMF, EB Oscherov and AZ Legal 2007. Pediculosis and other parasitosis in a northeast Argentine children population. Parasitologia Latinoamericana 62(1/2): 83-88.

16. Rios SM, JA Fernández, F Rivas, ML Sáenz and LI Moncada 2008. Pediculosis prevalence and associated risk factors in a nursery school, Bogotá, Colombia. Biomedica 28(2): 245-251.

17. David A, MD Guss, MD Mark Koenig and M Edward 2011. Severe iron deficiency anemia and lice infestation. J. Emerg. Med. 41(4): 362-365.

(Manuscript received on 4 November, 2013; revised on 15 June, 2014) 